\title{
ASSISTED CIRCULATION FOR THE RELIEF OF RIGHT HEART STRAIN
}

\author{
BY \\ W. H. BAIN, M. M. GLOVER, AND W. A. MACKEY \\ From the St. Mungo Department of Surgery and Royal Infirmary, University of Glasgow
}

Received August 2, 1961

Early in the development of mechanical pump-oxygenators several workers foresaw their application to the relief of acute heart failure (Helmsworth, 1952; Constantini, 1953; Newman, 1955; Stuckey, 1957). These attempts were only partially successful, probably because of the physiological upset after prolonged partial body perfusion with the apparatus then available. In the past few years, more experimental work has been done on the effects of prolonged partial heart and lung bypass (Galletti and Salisbury, 1958; Galletti and Brecher, 1960; Wyman et al., 1959) and recently further reports of the clinical application of this technique have appeared (Connolly et al., 1958; Dickson et al., 1960). The present communication describes the effect of partial heart/lung bypass on induced right ventricular and pulmonary arterial hypertension in the dog.

\section{EXPERIMENTAL Preparation}

This is shown diagrammatically in Fig. 1. Twenty-four adult mongrel dogs were used. Their weights ranged from 7 to 14 kilograms and the animals were anæsthetized with intravenous pentobarbitone. An intravenous infusion of 5 per cent dextrose in water containing $50 \mathrm{mg}$. succinylcholine and 50 milli-equivalents sodium bicarbonate in $200 \mathrm{ml}$. at a rate of $20-30$ drops per minute was given throughout the experiment. Intermittent positive pressure respiration was maintained with a Palmer pump, connected to a Benedict-Roth spirometer on which the oxygen uptake was measured. The heart was exposed through a right thoracotomy and pressures in the aorta, right atrium, right ventricle and pulmonary artery were monitored through catheters connected to Statham P23D strain gauges and recorded on an Ediswan direct writer. The animals were heparinized ( $3 \mathrm{mg}$. $/ \mathrm{kilo}$ with a supplementary half dose after 2 hours).

Various degrees of pulmonary hypertension were induced by embolizing the pulmonary arterioles with fine glass beads (average diameter $-0.1 \mathrm{~mm}$.) injected into the main pulmonary artery.

The extra-corporeal circuit was of a capacity to yield up to 60 per cent of the animal's cardiac output. A venous catheter introduced into the inferior vena cava through a femoral vein drained by gravity-siphonage into a small bubble oxygenator (made by Lusterlite Ltd., Leeds) and the arterialized blood was returned by pump through a cannula in the femoral artery The animal's temperature was monitored with an œsophageal thermocouple and maintained at normal during the procedure by means of heating lamps under the operating table. The pump oxygenator had its own heating system. The $\mathrm{pH}, \mathrm{pCO}_{2}$ and standard bicarbonate values of the blood were measured and the mild metabolic acidosis associated with prolonged pentobarbitone anæsthesia was controlled by infusion of sodium bicarbonate solution.

The cardiac output at different stages in each experiment was measured using the Fick principle. Mixed venous samples were taken from the right ventricle and arterial samples from the ascending 


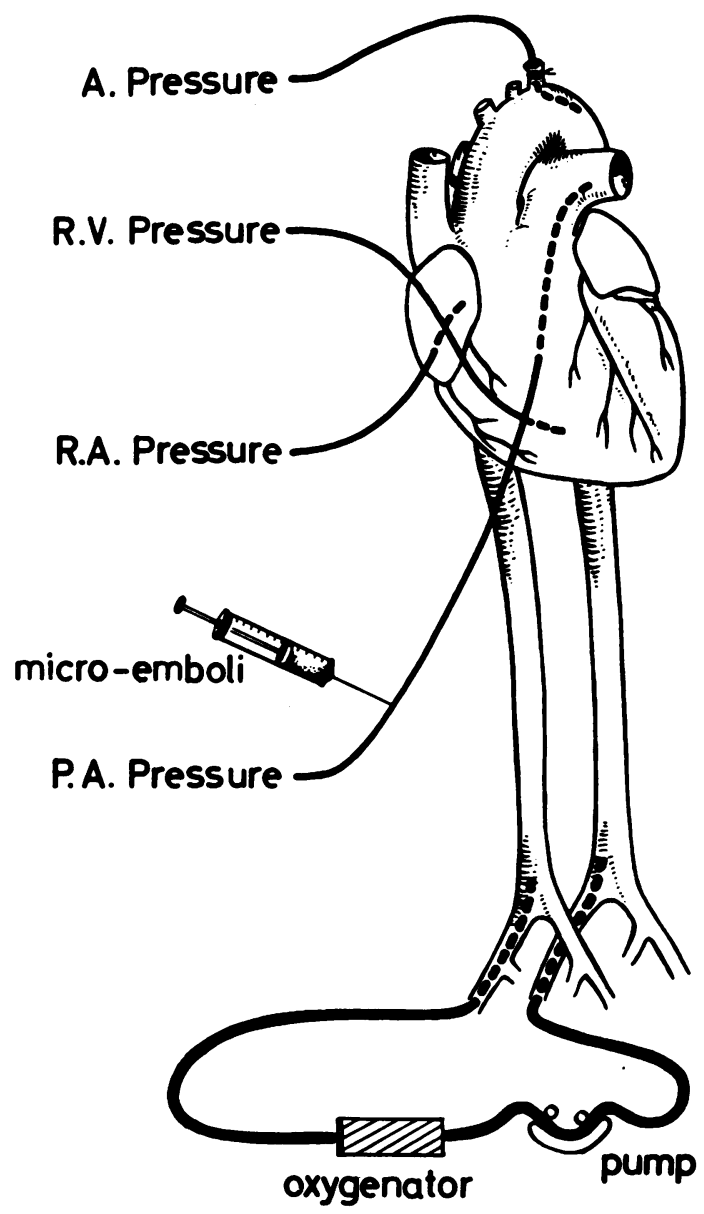

FiG. 1.-Diagram of experimental preparation and recording catheters.

aorta. Great care was taken to maintain normovolæmia, for example the blood withdrawn in the many samples was quantitatively replaced.

\section{RESULTS}

Some preliminary experiments were done to determine the basic hæmodynamics of this type of partial bypass.

The extracorporeal circuit acted in effect like a continuous venesection wherein the blood withdrawn was returned to the arterial side of the circulation. Accordingly it was found that the cardiac output measured during partial bypass was reduced by an amount equal to the output of the pumping system (Table I). The bypass circuit perfused the lower part of the body while the heart perfused the upper part, and the site of the watershed in the aorta depended on the relation between the outputs of the pump and of the heart. With the pump set to deliver 40 per cent of the control cardiac output, the watershed was just below the renal arteries. Under control conditions this volume of venoarterial pumping had no effect on the normal aortic or right heart pressures. After two hours' partial bypass the plasma hæmoglobin was $40 \mathrm{mg}$. per cent. The effect of injection of 
TABLE I

Cardiac OutPut-Bypass OutPut

\begin{tabular}{|c|c|c|c|}
\hline $\begin{array}{c}\text { Control } \\
\text { Cardiac output }\end{array}$ & $\begin{array}{l}\text { Cardiac output } \\
\text { during bypass }\end{array}$ & Bypass output & Sum \\
\hline $\begin{array}{r}500 \\
1020 \\
500 \\
1000 \\
1050 \\
1050 \\
500\end{array}$ & $\begin{array}{l}260 \\
740 \\
250 \\
585 \\
860 \\
670 \\
170\end{array}$ & $\begin{array}{l}200 \\
200 \\
300 \\
400 \\
120 \\
300 \\
300\end{array}$ & $\begin{array}{l}460 \\
940 \\
550 \\
985 \\
980 \\
970 \\
470\end{array}$ \\
\hline Mean & 505 & 260 & 765 \\
\hline
\end{tabular}

micro-emboli into the pulmonary circulation was assessed (Fig. 2) after an interval of 60 minutes had elapsed to allow stabilization. The systemic pressure fell, the systolic pressure in the right ventricle and pulmonary artery was doubled, and while the diastolic pressure in the pulmonary artery rose in a commensurate manner with some widening of the pulse pressure, the diastolic pressure in the right ventricle changed little, and in fact usually fell by two or three $\mathrm{mm}$. $\mathrm{Hg}$. The cardiac output was reduced by 10 to 15 per cent when sufficient emboli had been injected to double the right ventricular
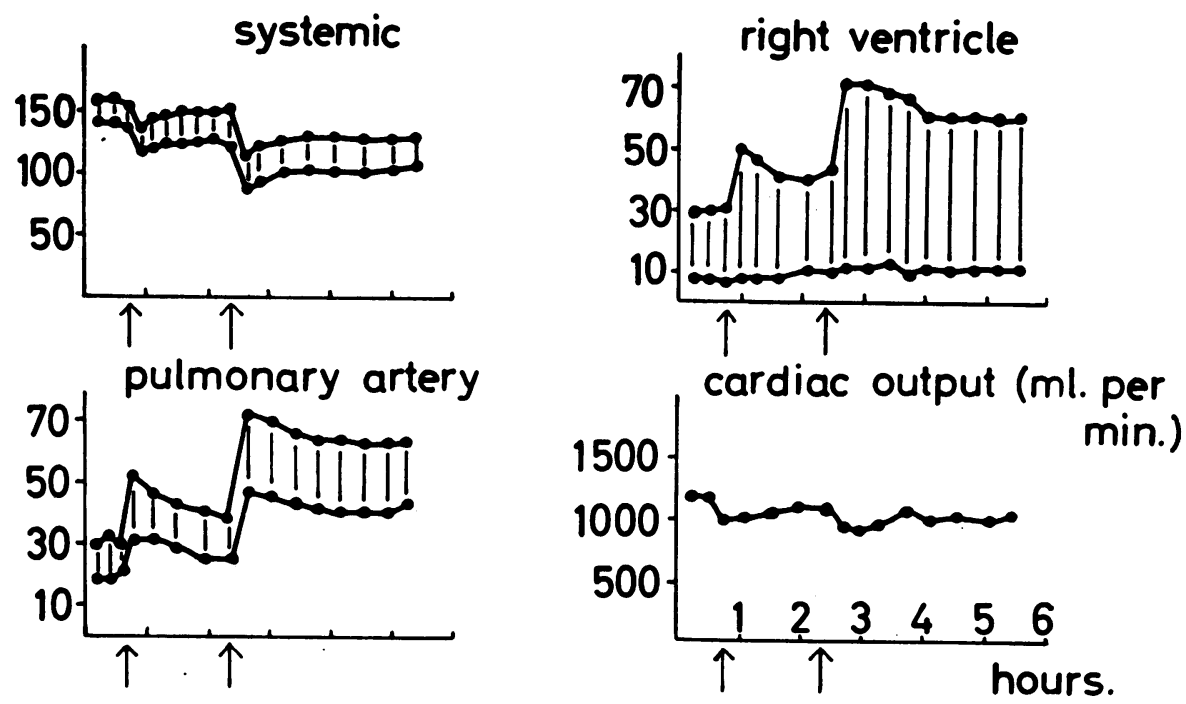

Fig. 2.-Effect of pulmonary micro-emboli on pressures (in $\mathrm{mm}$. $\mathrm{Hg}$ ). Mean values in 15 dogs.

systolic pressure. The tricuspid valve remained competent in all the preparations and the only change noted in the right atrial pressures was a rise of about $1 \mathrm{~mm}$. $\mathbf{H g}$ in diastole. The heart rate fell immediately after each injection of glass beads, but when the pressures had stabilized (within 30 minutes of injection) the rate had returned to the previous value.

The effect of partial bypass is shown in Fig. 3, 4, and 5. The systolic and mean pressures in the right ventricle and pulmonary artery were reduced significantly. The diastolic pressure in the pulmonary artery was also reduced. The systemic pressure was not, however, significantly raised. 

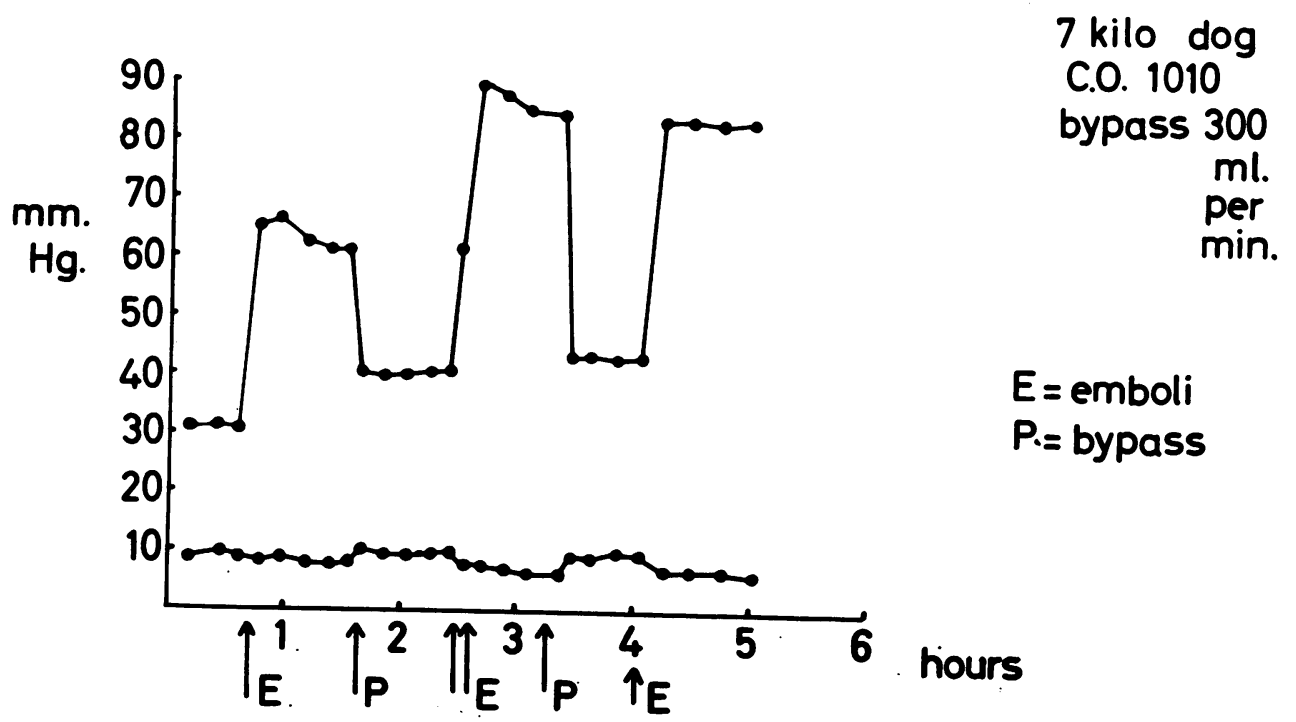

FIG. 3.-Effect of pulmonary micro-emboli and of veno-arterial bypass on right ventricular pressure.

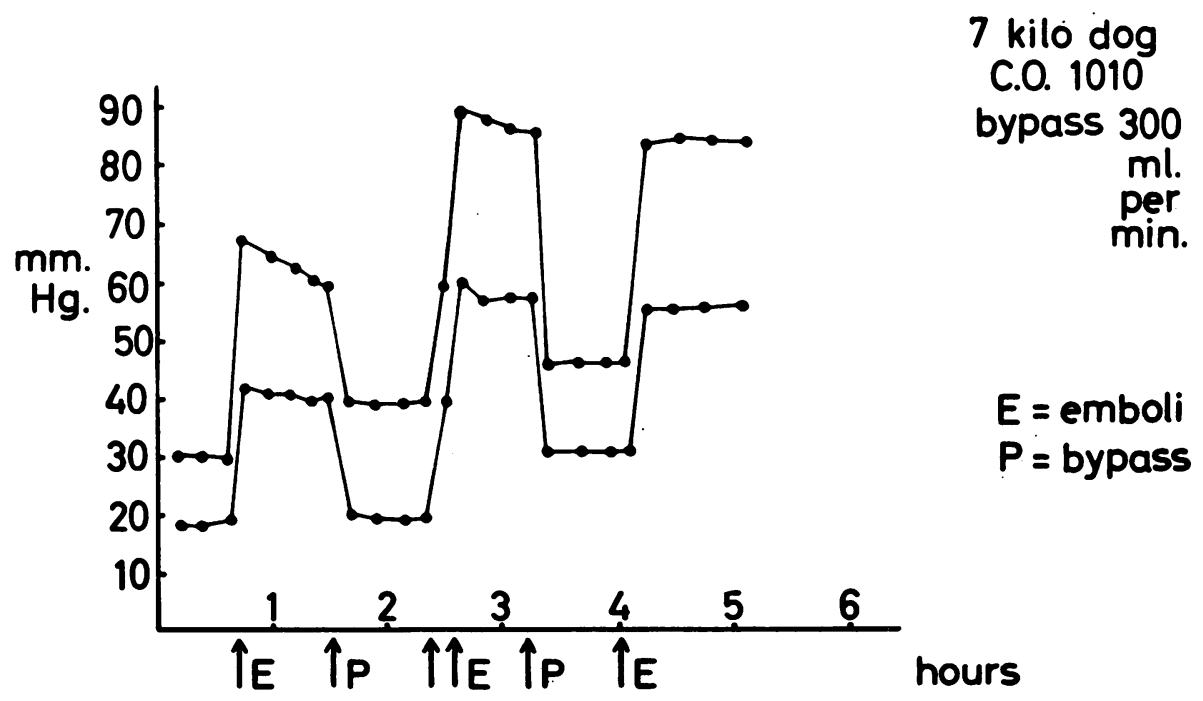

Fig. 4. -Effect of pulmonary micro-emboli and of veno-arterial bypass on pulmonary arterial pressure. 


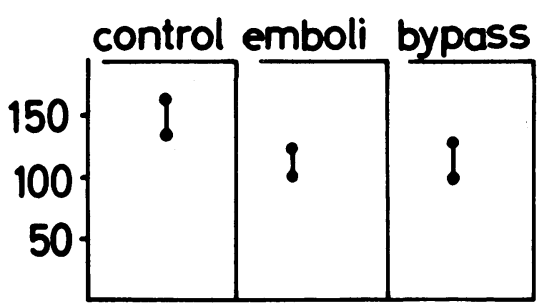

systemic B.P.

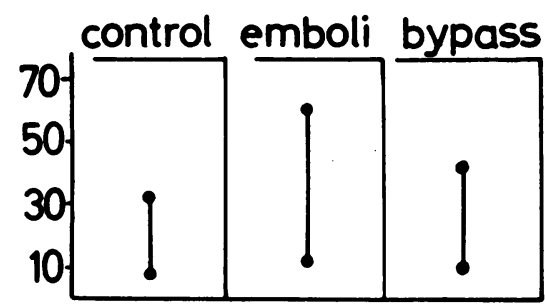

Pr. right ventricle

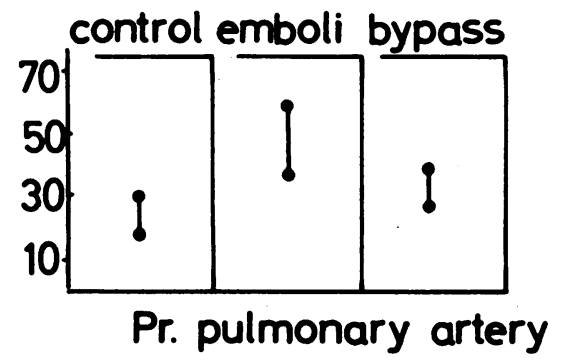

Fig. 5.-Effect of pulmonary micro-emboli and of veno-arterial bypass on blood pressures. Mean values of 15 dogs.

\section{Discussion}

The experiment was designed to find out whether partial heart-lung bypass would diminish pulmonary hypertension and reduce right ventricular work. The latter can be assessed approximately in terms of "external work", "internal work" and oxygen consumption. The results of this experiment show that partial bypass significantly reduces the external work of the right ventricle (measured as the product of the mean pressure and stroke volume). There were not sufficient data to measure "internal work" or the myocardial energy expended (as measured by oxygen consumption). Other workers have shown that the energy expenditure of the left ventricle during partial bypass in normal dogs was unaltered despite diminished cardiac filling, as long as the blood pressure and blood volume were constant (Galletti and Salisbury, 1959; Salisbury et al., 1959). The work of the left ventricle measured as the tension-time index (Sarnoff $e$ t al., 1958) is probably related most directly to the aortic pressure (Gerein et al., 1960) as is also the coronary blood flowso that an extracorporeal support which raises the aortic pressure and increases coronary flow might well also increase left ventricular work. In the case of right ventricular overload, however, partial bypass would seem to reduce both the external and internal work-load by lowering the pressures in that ventricle and in the pulmonary artery. Nevertheless, further experiments in which more data are collected are required to show how much the energy requirements of the heart are increased by acute pulmonary hypertension and by how much partial bypass will reduce these requirements. Our results are in accord with those of Rutherford and Swan (1960) and Storli et al. (1960) in showing that partial bypass can be maintained for several hours without harm, provided that changes in $\mathrm{pH}$ are corrected.

\section{SUMmary}

Pulmonary arterial hypertension was induced acutely in dogs. Partial heart and lung bypass was instituted and its effect measured in terms of changes in pressures and cardiac output. The bypass reduced the systolic and mean pressures in the right ventricle and pulmonary artery, and reduced the external work of the right ventricle.

The authors are grateful for the excellent facilities afforded in the Wellcome Research Laboratories of the University of Glasgow, where this work was done. 


\section{REFERENCES}

Connolly, J. E., Bacaner, M. B., Bruns, D. L., Lowenstein, J. M., and Storli, E. (1958). Surgery, 44, 255.

Constantini, A., Poli, G. D., Caldarola, L., Pironti, L., and Besse, C. (1953). Minerva med., 44, 1272.

Dickson, J. F., Hamer, N. A. J., and Dow, J. W. (1960). Arch. Surg., Chicago, 80, 830.

Galletti, P. M., and Salisbury, P. F. (1958). Trans. amer. Soc. Artificial Internal Organs, 4, 157.

- -, (1959). J. appl. Physiol., 14, 684.

- , and Brecher, G. A. (1960). Circulat. Res., 8, 609.

Gerein, A. N., Jones, B. A., and Cross, F. S. (1960). Surg. Forum, 11, 212.

Helmsworth, J. H., Clark, L. C., Kaplan, S., Sherman, R. T., and Largen, T. L. (1952) J. amer. med. Ass., 150, 451.

Newman, M. M., Stuckey, J. H., Levowitz, B. S., Young, L. A., Dennis, C., Fries, C., Gorayeb, E. J., Zuhdi, M. Karlson, K. E., Adler, S., and Gliedman, M. (1955). Surgery, 38, 30.

Rutherford, R. B., and Swan, H. (1960). Surg. Forum, 11, 212.

Salisbury, P. F., Bor, N., Lewin, R. J., and Rieben, P. A. (1959). J. appl. Physiol., 14, 458.

Sarnoff, S. J., Braunwald, E., Welch, G. H., Case, R. B., Stainsby, W. N., and Macruz, R. (1958). Amer. J. Physiol., $192,148$.

Storli, E., Connolly, J. E., Bacaner, M. B., and Bruns, D. L. (1960). Surg. Forum, 11, 214.

Stuckey, J. H., Newman, M. M., Dennis, C., Berg, E. H., Goodman, S. E., Fries, C. C., Karlson, K. E., Blumenfeld, M., Weitzner, S. W., Binder, L. S., and Winston, A. (1957). Surg. Forum, 8, 342.

Wyman, M. G., Weil, M. H., and Blankenhorn, D. H. (1959). J. clin. Invest., 38, 1056. 